UNDERGRADUATE RESEARCH IN NATURAL AND CLINICAL SCIENCE AND TECHNOLOGY (URNCST) JOURNAL Read more URNCST Journal articles and submit your own today at: https://www.urncst.com

\title{
Introduction to Knowledge Translation in Health Care Research
}

\author{
Shahzadi Zain, MBBS, MPH Student [1], Umair Majid, MSc, MEd, PhD Student [2,3,4]* \\ [1] Schulich School of Medicine and Dentistry, University of Western Ontario, London, \\ Ontario, Canada \\ [2] Managing Editor, URNCST Journal, Toronto, Ontario, Canada \\ [3] Institute of Health Policy, Management, and Evaluation, University of Toronto, Ontario, \\ Canada \\ [4] Toronto General Hospital Research Institute, University Health Network, Toronto, Ontar- \\ io, Canada
}

*Corresponding Author: umair.majid@mail.utoronto.ca

\begin{abstract}
Knowledge translation may be understood as the process of synthesizing, disseminating, and exchanging information to appropriate audiences. This process is an essential component of research, ensuring that research findings reach the knowledge users in a cost-efficient and meaningful manner. However, novice investigators may sometimes believe knowledge translation equates to presentations at research conferences and publishing in a journal. The objective of this paper is to address this misconception by providing an overview of the knowledge translation process for novice investigators. The authors will first define knowledge translation and describe its importance in health care research. Following this brief introduction, a framework for knowledge translation, the Knowledge-to-Action Cycle, will be examined to equip novice investigators with the essential knowledge and strategies they need to develop and implement successful research proposals. The information presented in this paper may enable novice investigators to understand and apply knowledge translation in their research, enhancing its applicability and usefulness. The authors conclude this paper by clarifying the various approaches, levels, and means of knowledge translation, and by constructing a brief overview of planning considerations for novice investigators engaging in knowledge translation.
\end{abstract}

Keywords: knowledge translation; implementation science; undergraduate research; clinical research; knowledge transformation; knowledge utilization; knowledge exchange; knowledge dissemination

\section{Introduction}

Health care research contributes concepts, theories, and facts to the evidence base that are meant to guide clinical practice and meet the diverse needs of patients, families, care partners, clinicians, decision-makers, and administrators [1]. To direct limited health care funding, investigators should clearly communicate the impact of their research on clinical practice, health policy, and patient experiences. This effort will also guide diverse stakeholder groups through deliberation for policy development and for making decisions regarding resource allocation, research priorities, and management structures [2]. Currently, health policies and clinical guidelines lag behind research knowledge because of the discrepancies between knowledge synthesis and knowledge use [3].

Knowledge translation (KT) is of critical importance in health care research as it becomes clearer that the production of new and theoretically useful knowledge does not necessarily lead to a positive impact on health and health care [4]. The process of KT may also help to determine the utility of the knowledge produced from a research investigation. Even a tool or intervention demonstrated as efficacious can be ineffective if factors such as access to knowledge, the relevance, reliability, applicability, trustworthiness of the research findings, and the views of key stakeholders, are not taken into consideration in the use of the tool or intervention [5]. The gap between knowledge discovery and action may be reduced by using KT strategies that disseminate already existing research knowledge effectively to health policy, interventions, and clinical practice.

The majority of funding agencies require investigators to incorporate strategies for KT in their grant proposal. Successful research proposals tend to integrate KT throughout the research cycle and demonstrate positive, tangible impacts to their funding agencies [6]. The Canadian Institutes of Health Research (CIHR), for example, ensures that investigators are held accountable for the implementation component of their research findings, including $\mathrm{KT}$, by conditioning the funding with a mid-term report, 
UNDERGRADUATE RESEARCH IN NATURAL AND CLINICAL SCIENCE AND TECHNOLOGY (URNCST) JOURNAL Read more URNCST Journal articles and submit your own today at: https://www.urncst.com

final report, and/or attendance at annual research meetings [7]. In these cases, novice investigators may be confused about the different requirements and components of $\mathrm{KT}$ included in research projects. Therefore, a discussion that describes and clarifies KT is an imperative for novice investigators to engage in the use and implementation of research knowledge.

The objective of this paper is to introduce the foundations and importance of KT. This paper will describe various elements of KT and highlight its vitality in health care research. The Knowledge-to-Action Cycle is used as a framework to help novice investigators clarify the nuances of KT across their research activities. As a conclusion to this paper, the authors will outline different approaches to efficient KT and provide an overview of planning considerations for novice investigators to conceptualize and operationalize $\mathrm{KT}$ in their research projects.

\section{$\underline{\text { KT Definitions and Terminologies }}$}

There is a strong desire to demonstrate the applicability and transferability of research knowledge, which has contributed to the acknowledgement and proliferation of KT in health care research. KT is not a novel concept and its description in literature dates to the 1910s in various forms [8]. According to the CIHR, KT is "a dynamic and iterative process that includes the synthesis, dissemination, exchange and ethically-sound application of knowledge to improve the health of Canadians, provide more effective health services and products, and strengthen the health care system" [9]. This definition has two components, the first of which explicates the different elements of KT. The second part of the definition illustrates the key objective of KT; that the health of Canadians should be improved through effective health services and a strong health system, which may be only achieved by closing the gaps between knowledge production and knowledge implementation.

\section{The Knowledge-to-Action Cycle}

The Knowledge-to-Action Cycle conceptualizes the relationship between the creation and implementation of knowledge [10]. The first component of this framework is Knowledge Creation consisting of three phases through Various terminologies have been used to identify KT. Although KT is the most commonly used term in Canada, other terms include knowledge transfer, knowledge exchange, knowledge utilization, and knowledge dissemination [10]. These terms, although similar in meaning, may emphasize different aspects of KT. However, there is no consensus on the differences between these terms. Graham et al. (2006) compared the definition of KT by CIHR and US National Center for the Dissemination of Disability Research (NCDDR) and found that both emphasize the need to address the gap between knowledge production and its use. The NCDDR's definition elaborates further on the KT process as inherently collaborative and multidirectional among all stakeholders of the health care system [10].

which knowledge becomes more sensitive to the audience and suitable for dissemination and action (Table 1).

This framework depicts a positive feedback loop whereby newly designed tools enhance the way investigators prioritize research questions and conduct research. The second component of the Knowledge-to-Action framework is the Action Cycle, which is comprised of eight phases:

1) Identify problem

2) Identify, review, and select knowledge

3) Adapt knowledge to the relevant contexts

4) Assess the barriers to knowledge use

5) Select, tailor, and implement KT strategies

6) Monitor the use of knowledge

7) Evaluate the outcomes of KT strategies

8) Sustain KT in the relevant contexts

\section{Two Types of KT}

There are two types of KT: End-of-Grant KT and Integrated $K T$ [7]. The primary purpose of end-of-grant KT is to disseminate the findings of a research activity to appropriate audiences. In this form of KT, the funding proposal should describe the strategy for KT and the application of research findings to health policy and clinical practice [7]. End-of-grant KT may be accomplished through various strategies such as: scientific writing (i.e., publishing manuscripts in journals); educational sessions for patients, families, and care partners; stakeholder meetings and briefing sessions; and presentations at conferences.

Integrated KT also involves the translation of knowledge to appropriate audiences, but unlike end-of-grant KT, it occurs throughout the life cycle of a research study [7]. This type of KT aims to not only disseminate knowledge to users at the start of the research study but also include knowledge users as research partners [7].

Table 1: Descriptions of Three Phases of Knowledge Creation

\begin{tabular}{|l|l|}
\hline Knowledge Creation Phase & Description \\
\hline Knowledge Inquiry & $\begin{array}{l}\text { The assessment and review of existing knowledge, and conducting primary research } \\
\text { to address current gaps }\end{array}$ \\
\hline Knowledge Synthesis & $\begin{array}{l}\text { The integration of the novel findings produced by primary research into the evi- } \\
\text { dence base }\end{array}$ \\
\hline Products/Tools & $\begin{array}{l}\text { The development of decision-making tools, procedures, and clinical guidelines to } \\
\text { inform practice and policy }\end{array}$ \\
\hline
\end{tabular}


UNDERGRADUATE RESEARCH IN NATURAL AND CLINICAL SCIENCE AND TECHNOLOGY (URNCST) JOURNAL Read more URNCST Journal articles and submit your own today at: https://www.urncst.com

For example, a research study that aims to develop a toolkit for increasing maternal awareness during pregnancy and childbirth may require researchers to consult child-bearing women about the research questions, data collection procedures, sampling protocols, and the most appropriate KT strategies [12].

Consulting knowledge users at each step of the research process work is more likely to produce outcomes that are more relevant and useful to the knowledge users as exemplified in the Family Help example. Family Help is a mental health delivery system designed to provide child mental health services. The participation of family, physicians, and other health care professionals early in the research phase resulted in wide acceptance of the Family Help delivery system, increasing its sustainability and applicability beyond the research context [12].

\section{Factors Influencing KT}

Whether it is the end-of-grant KT or integrated KT, messages should be tailored to enhance usefulness and applicability for appropriate stakeholder groups. Some of the factors to consider when constructing appropriate KT activities are: the goals of the KT strategies, the characteristics of the knowledge users, the expertise of researchers, and the resources available to the research team [7]. The goals of KT strategies may dictate to whom the research findings are delivered. For example, if the goal of KT is to raise awareness among the general population, then KT messages should be simple, comprehensible, and use lay language. On the other hand, if the goal is to inform future research, then the language may be more technical and include scientific jargon because the primary audience are funding agencies and researchers. Similarly, the characteristics of knowledge users are relevant to the level of KT (see below) because the tools, language, and KT settings will differ between intended audience. The expertise of researchers influence how effectively KT is applied across research thereby determining the credibility and trustworthiness of KT practices. Finally, the availability of resources is an important factor in deciding what, where, and how knowledge will be disseminated. If there are limited resources available to the research team, then KT may be implemented incompletely or concluded prematurely.

It is also important to clarify the levels at which KT may occur. Distinct levels may require different KT strategies, as dependent on the primary audience, population context, and political environment. KT may occur at following levels [13]:

- Individual people

- Individual health care professionals

- Groups of caregivers

- Hospitals

- Local areas (i.e., municipalities, cities)

- States or provinces

Zain et al. | URNCST Journal (2018): Volume 2, Issue 11 DOI Link: https://doi.org/10.26685/urncst.67
- Nations

- Managers or decision-makers

- Policy-makers (regional, national, and international)

\section{KT Strategies}

Methods useful for translating research findings range from simple communication exercises such as oral presentations to more sophisticated knowledge application efforts such as Delphi consensus meetings. Traditionally, knowledge has been disseminated by publishing books, journals, and media reports. The process of publishing has been modified over time depending on the urgency to produce knowledge by various stakeholders. For example, in emergency situations such as epidemics, KT may rely more on rapid communication [11]. In these cases, KT may be facilitated through manuscript preprints made openly available online without a complete peer review. This may provide an opportunity for clinicians and investigators to accelerate the dissemination and implementation of scientific findings [14].

In decision-making deliberations, there is a demand for more interactive KT strategies and tools such as workshops, worksheets, Internet postings, and illustrative diagrams [15]. The Canadian Breast Cancer Screening Initiative (CBCSI), for example, uses a combination of illustrative diagrams, lay language, and worksheets to prepare a decision aid for breast cancer patients, by converting technical medical information in a simple and easy format [16]. Technical KT strategies are often intended for academic audiences whereas creative media including film, theatre, and artwork may be well-suited for academic and nonacademic knowledge users. The use of online technologies such as podcasting, webinars, and YouTube have revolutionized the KT landscape and expanded the way in which $\mathrm{KT}$ is understood and implemented. Moreover, in order to maximize impact of the findings from any study, the integration of multiple $\mathrm{KT}$ strategies into the research process is necessary.

\section{A Summary of Planning Considerations for Novice Investigators}

This section provides a brief overview of planning considerations for novice investigators who are engaging in KT or considering a KT component for their research project.

Review the types, methods, and strategies to KT, including their pros and cons, and examples of their application in a variety of contexts.

- Consider KT types and strategies during the process of formulating the research proposal, which in many cases, is a requirement of funding agencies.

- Engage in a peer-review process between colleagues and within the research team to ensure that the types and strategies to KT are appropriate, relevant, and holistic. 
UNDERGRADUATE RESEARCH IN NATURAL AND CLINICAL SCIENCE AND TECHNOLOGY (URNCST) JOURNAL Read more URNCST Journal articles and submit your own today at: https://www.urncst.com

- Identify possible solutions to reduce, address, or prepare for foreseeable challenges.

- $\quad$ Reflect on the KT types and strategies throughout the research process and determine in what ways the research project has achieved them.

- Delineate project SMART goals to improve the way KT continues after the research project.

- Communicate to all stakeholders the successes and areas for improvement concerning KT strategies that were implemented in the project.

\section{Conclusion}

$\mathrm{KT}$ is a process through which synthesized knowledge is disseminated in a way that is culturally-appropriate and reduces the discrepancies between knowledge and practice by improving the usefulness of research findings. This paper considered KT as a dynamic process whereby the three phases of knowledge creation (knowledge inquiry, knowledge synthesis, and products/tools) complement the eight phases of knowledge action (identify problem, identify, review, and select knowledge, adapt knowledge to the relevant contexts, assess the barriers to knowledge use, select, tailor and implement KT strategies, monitor the use of knowledge, evaluate the outcomes of KT strategies, and sustain KT in the relevant contexts) to produce practices and policies that are transferable to other contexts. Moreover, this paper differentiated between end-of-grant KT and integrated KT as two KT approaches with the aim to disseminate and apply research knowledge but with distinct approaches to engaging stakeholders. Finally, this paper provided an overview of planning considerations for novice investigators interested in using $\mathrm{KT}$ in their research.

\section{List of Abbreviations}

KT: Knowledge Translation

CIHR: Canadian Institute of Health Research

PHAC: Public Health Agency of Canada

CBCSI: Canadian Breast Cancer Screening Initiative

URNCST: Undergraduate Research in Natural and Clinical Science and Technology

\section{Conflicts of Interest}

The authors declare that they have no conflicts of interest.

\section{Ethics Approval and/or Participant Consent N/A}

\section{Authors' Contributions}

SZ and UM wrote the entire publication based on their experiences, knowledge and expertise in addition to the reviewing literature on the Knowledge Translation.

\section{Acknowledgements}

None.

\section{Funding}

This study was not funded.

\section{References}

[1] Dudley L, Gamble C, Preston J, Buck D, Hanley B, Williamson P, Young B, EPIC Patient Advisory Group. What difference does patient and public involvement make and what are its pathways to impact? Qualitative study of patients and researchers from a cohort of randomised clinical trials. PLoS one. 2015 Jun 8; 10(6):e0128817. https://doi.org/10.1371/journal.pone.0128817

[2] Haywood K, Marshall S, Fitzpatrick R. Patient participation in the consultation process: a structured review of intervention strategies. Patient education and counselling. 2006 Oct 1; 63(1):12-23. https://doi.org/10.1016/j.pec.2005.10.005

[3] Jansen, M., van Oers, H., Kok, G. and de Vries, N. (2010). Public health: disconnections between policy, practice and research. Health Research Policy and Systems, 8(1). https://doi.org/10.1186/1478-4505-8-37

[4] Collier, R. (2016). Is most clinical research useless? Canadian Medical Association Journal, 188(11), pp.790-791. https://doi.org/10.1503/cmaj.109-5296

[5] Albert MA, Fretheim A, Maïga D. Factors influencing the utilization of research findings by health policymakers in a developing country: the selection of Mali's essential medicines. Health Research Policy and Systems. 2007May; 5(1). http://doi.org/10.1186/14784505-5-2

[6] Kanji S. Turning Your Research Idea into a Proposal Worth Funding. The Canadian Journal of Hospital Pharmacy. 2015;68(6).

[7] Cihr-irsc.gc.ca. (2015). Guide to Knowledge Translation Planning at CIHR: Integrated and End-of-Grant Approaches - CIHR. [online] Available at: http://www.cihr-irsc.gc.ca/e/45321.html\#a7 [Accessed 10 Jun. 2018].

[8] Azimi A, Fattahi R, Asadi-Lari M. Knowledge translation status and barriers. Journal of the Medical Library Association: JMLA. 2015 Apr;103(2):96. http://doi.org/10.3163/1536-5050.103.2.008

[9] Government of Canada, Canadian Institutes of Health Research, Institute Affairs. Knowledge translation [Internet]. CIHR. 2017 [cited 2018Jun21]. Available from: http://www.cihr-irsc.gc.ca/e/29529.html

[10] Graham, I., Logan, J., Harrison, M., Straus, S., Tetroe, J., Caswell, W. and Robinson, N. (2006). Lost in knowledge translation: Time for a map? Journal of Continuing Education in the Health Professions, 26(1), pp.13-24. https://doi.org/10.1002/chp.47

[11] Joffe S. Evaluating novel therapies during the Ebola epidemic. Jama. 2014 Oct 1; 312(13):1299-300. http://doi.org/10.1001/jama.2014.12867

[12] McGrath PJ, Lingley-Pottie P, Emberly DJ, Thurston $\mathrm{C}, \mathrm{McLean} \mathrm{C}$. Integrated knowledge translation in 
UNDERGRADUATE RESEARCH IN NATURAL AND CLINICAL SCIENCE AND TECHNOLOGY (URNCST) JOURNAL Read more URNCST Journal articles and submit your own today at: https://www.urncst.com

mental health: family help as an example. Journal of the Canadian Academy of Child and Adolescent Psychiatry. 2009 Feb; 18(1):30.

[13] Grimshaw JM, Eccles MP, Lavis JN, Hill SJ, Squires JE. Knowledge translation of research findings. Implementation science. 2012 Dec; 7(1):50. https://doi.org/10.1186/1748-5908-7-50

[14] Hunt M, Tansey CM, Anderson J, Boulanger RF, Eckenwiler L, Pringle J, Schwartz L. The challenge of timely, responsive and rigorous ethics review of disaster research: views of research ethics committee members. PLoS one. 2016 Jun 21; 11(6):e0157142. https://doi.org/10.1371/journal.pone.015714

[15] Public Health Agency of Canada (2012). Knowledge Translation (KT) Planning Primer.

[16] Public Health Agency of Canada (2011). A Decision Aid for Breast Cancer Screening in Canada

\section{Article Information}

Managing Editors: Jae Hyun Byun, Jeremy Y. Ng

Peer Reviewers: Meghan Mullaly, Victoria Zefkic

Article Dates: Received Jun 26 18; Accepted Oct 23 18; Published Nov 2118

\section{Citation}

Please cite this article as follows:

Zain S, Majid U. Introduction to knowledge translation in health care research. URNCST Journal. 2018 Nov 21: 2(11).

https://urncst.com/index.php/urncst/article/view/67

DOI Link: https://doi.org/10.26685/urncst.67

\section{Copyright}

(C) Shahzadi Zain, Umair Majid. (2018). Published first in the Undergraduate Research in Natural and Clinical Science and Technology (URNCST) Journal. This is an open access article distributed under the terms of the Creative Commons Attribution License (https://creativecommons.org/licenses/by/4.0/), which permits unrestricted use, distribution, and reproduction in any medium, provided the original work, first published in the Undergraduate Research in Natural and Clinical Science and Technology (URNCST) Journal, is properly cited. The complete bibliographic information, a link to the original publication on http://www.urncst.com, as well as this copyright and license must be included.

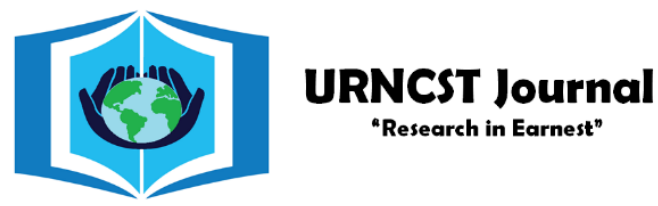
Funded by the Government of Canada

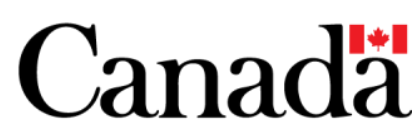

Do you research in earnest? Submit your next undergraduate research article to the URNCST Journal!

| Open Access | Peer-Reviewed | Rapid Turnaround Time | International | | Broad and Multidisciplinary | Indexed | Innovative | Social Media Promoted |

Pre-submission inquiries? Send us an email at info@urncst.com | Facebook, Twitter and LinkedIn: @URNCST

Submit YOUR manuscript today at https://www.urncst.com! 